\title{
Palliative radiation therapy for patients with orbital and ocular metastases
}

\author{
Jeannie Y. K. Chik, Carmen W. L. Leung, Kam Hung Wong \\ Department of Clinical Oncology, Queen Elizabeth Hospital, Kowloon, Hong Kong, China \\ Contributions: (I) Conception and design: JY Chik; (II) Administrative support: JY Chik; (III) Provision of study materials or patients: JY Chik; (IV) \\ Collection and assembly of data: JY Chik; (V) Data analysis and interpretation: JY Chik; (VI) Manuscript writing: All authors; (VII) Final approval of \\ manuscript: All authors. \\ Correspondence to: Jeannie Y. K. Chik. Department of Clinical Oncology, Queen Elizabeth Hospital, Kowloon, Hong Kong, China. \\ Email: cyk632@ha.org.hk.
}

Background: Patients with cancer may develop metastases to the orbit causing distressing symptoms. External beam radiation therapy (RT) is an effective palliative treatment for patients with orbital and ocular metastases. The aim of treatment is to preserve vision and to reduce pain. Delivery of 30 to $40 \mathrm{~Gy}$ in $2 \mathrm{Fr}$ fractions is a practice in many oncology centres. The aim of this study is to evaluate the outcome of shortcourse palliative radiotherapy in the management of orbital and ocular metastases.

Methods: A retrospective study to review all patients with orbital metastases treated in 2016 to 2018 were performed. The primary outcomes were a change in visual acuity and tumor response. Secondary outcomes included toxicities of radiotherapy, symptomatic response and survival.

Results: Fifteen patients with 19 eyes were included. The most common presenting symptoms were decreased vision, periorbital swelling, and pain. The median follow-up period was 8 months. Visual acuity improved in 11 out of $13(84.6 \%)$ of patients and remained stable in the remaining 2 patients. Partial and complete response (CR) of tumor was observed in 14 out of 15 (93.3\%) of patients while one $(6.6 \%)$ patient had stable disease. The overall response rate (ORR) was $100 \%$. Two (13.3\%) patients had grade 2 conjunctivitis. There were no grade 3-4 toxicities and no long-term toxicities observed. The median survival was 9.1 months from diagnosis of choroidal metastases.

Conclusions: Short course palliative RT is effective and well tolerated in patients with orbital and ocular metastases. The current review showed that it effectively preserves vision and improves orbital symptoms with minimal radiation-induced toxicity. Short course radiotherapy will help to minimize the traveling time to the hospital and relieve the burden of a long treatment course in this palliative patient population.

Keywords: Eye metastases; choroid metastases; palliative treatment; radiation therapy (RT); eye complication; orbital metastases

Submitted Apr 10, 2019. Accepted for publication Nov 25, 2019.

doi: 10.21037/apm.2019.12.02

View this article at: http://dx.doi.org/10.21037/apm.2019.12.02

\section{Introduction}

Tumors that involve the orbit are divided into intraocular tumors and extraocular tumors. Among intraocular tumors, metastases to the uveal tract are the most common. The potential reason for such pattern of metastasis is due to the high vascular supply of the uveal tract which increases the chance of tumor deposits by hematogenous spread. Choroidal metastases account for $88 \%$ of cases followed by metastases to the iris and the ciliary body. Breast (37-41\%), lung $(7 \%)$ and colon carcinomas are common malignancies which cause choroidal secondaries $(1,2)$. The overall incidence of choroidal metastases is $9-12 \%$ in all cancers and commonly present with decreased visual acuity (3). 
Extraocular orbit metastases, however, is rare and occur less frequently than metastases to the uveal tract (4). The prevalence of extraocular orbital metastases in cancer patients is estimated to range from $2-4.7 \%$ (5). Metastatic orbital lesions account for $1-13 \%$ of all orbital tumors. Common symptoms include periorbital mass, proptosis, diplopia, decreased vision and pain (5). Orbital and ocular metastases occur through the hematogenous route and are an ominous sign of advanced systemic disease with overall survival (OS) of usually less than 12 months $(6,7)$. With the current advances in the systemic treatment for cancers in general, the median survival of patients increases and so will the chance of developing metastases to these unusual sites. Furthermore, vigilant surveillance together with the advancement in diagnostic imaging also increase the detection rate of these lesions which may have remain undetected in the past. Orbital and ocular metastases cause significantly disturbing symptoms and these include decreased visual acuity and pain. These disabling symptoms add on to the sufferings that these patients are already experiencing. It is therefore important to have a treatment that is effective for controlling these symptoms without causing much toxicity and be simple and easy to administer. Treatment is aimed both at preserving vision and improving symptom control for the remainder for the patient's life. We reviewed the results of palliative radiation therapy (RT) in the management of orbital and choroidal metastases.

\section{Methods}

A retrospective study was performed. Fifteen patients with orbital metastases who received palliative radiotherapy in Queen Elizabeth Hospital, Hong Kong during the period from $1^{\text {st }}$ January 2016 to $31^{\text {st }}$ December 2018 were included in the analysis. The hospital records of these patients were reviewed. All information regarding the primary cancer site, date of diagnosis, symptoms on presentation, visual acuity, ophthalmologic investigations, RT dose and technique and patient survival was recorded. The primary outcomes were a change in visual acuity and tumor response. Secondary outcomes include symptom improvement, toxicities of radiotherapy and OS. Survival curves were determined by Kaplan-Meier method using the Statistical Package for the Social Sciences (Mac version 23). Toxicities were graded according to Common Terminology Criteria for Adverse Events Version 5.0.

\section{Results}

\section{Patient demographics}

Nineteen eyes of 15 patients with orbital metastases were included in the analysis. The patient demographic data were summarised in Table 1. Seven and 8 patients were male and female respectively. The median age was 67 years old (range, 14-98 years). The histology of the primary malignancies included lung $(4,26.7 \%)$, breast $(4,26.7 \%)$, lymphoma $(6,40.0 \%)$ and sarcoma (1, 6.7\%). Eleven (73.3\%) patients had unilateral ocular involvement while 4 patients $(26.7 \%)$ had bilateral ocular involvement. Eight patients had extraocular orbital metastases while 7 patients had choroidal metastases. The median interval period from the diagnosis of primary malignancy to the development of ocular or orbital metastases was 13 months (range, 1-61 months). The time to development of ocular or orbital metastases for breast cancer, lung cancer, and lymphoma were 24.6, 3.2 and 11.4 months respectively. With regards to the symptoms on presentation, 11 patients $(73.3 \%)$ presented with decreased visual acuity, $5(33.3 \%)$ patients presented with periorbital swelling, 2 (13.3\%) patients presented with eye pain, $1(6.7 \%)$ patient presented with proptosis, while $1(6.7 \%)$ patient presented with diplopia. Among the 7 patients with choroidal metastases, 2 patients $(28.5 \%)$ had retinal detachment on presentation.

\section{Treatment details}

Three $(20 \%)$ patients were treated with conventional 2 -D technique, while 12 patients $(80 \%)$ were treated with conformal technique. The commonly prescribed dose was 30 Gy in 10 fractions ( $n=5)$, followed by 20 Gy in 4 fractions $(n=4)$. Other dose fractionation used included 30 Gy in 15 fractions $(n=2), 6$ Gy in 1 fraction $(n=2)$, 4 Gy in 1 fraction $(n=1)$ and 24 Gy in 12 fractions $(n=1)$ (Table 2). For conventional 2D technique, patients were treated with either single anterior field for unilateral eye irradiation or lateral opposing fields to the orbits for bilateral eye irradiation. For conformal technique, target volume was defined as the involved globe with a $0.5 \mathrm{~cm}$ margin.

\section{Follow-up and outcome}

Site of metastases, the radiation dose given, symptoms improvement, tumor response and survival outcomes of the 
Table 1 Patient demographics

\begin{tabular}{|c|c|}
\hline Variable & Outcome $(n=15)$ \\
\hline \multicolumn{2}{|l|}{ Age (years) } \\
\hline Median & 67 \\
\hline Range & $14-98$ \\
\hline \multicolumn{2}{|l|}{ Sex, n (\%) } \\
\hline Male & $7(46.7 \%)$ \\
\hline Female & $8(53.3 \%)$ \\
\hline \multicolumn{2}{|l|}{ Primary cancer, n (\%) } \\
\hline Lung & $4(26.7 \%)$ \\
\hline Breast & $4(26.7 \%)$ \\
\hline Others & $7(46.7 \%)$ \\
\hline \multicolumn{2}{|c|}{ Orbital/ocular metastases, n (\%) } \\
\hline Unilateral & $11(73.3 \%)$ \\
\hline Bilateral & $4(26.7 \%)$ \\
\hline \multicolumn{2}{|l|}{ Location } \\
\hline Choroid & $7(46.7 \%)$ \\
\hline Extraocular orbit & $8(53.3 \%)$ \\
\hline \multicolumn{2}{|c|}{$\begin{array}{l}\text { Median time between diagnosis of primary } \\
\text { tumor and ocular metastases (months) }\end{array}$} \\
\hline Overall & 13 (range, 1-61) \\
\hline Breast cancer & 24.6 (range, 13-50) \\
\hline Lung cancer & 3.2 (range, 3.2-34.8) \\
\hline Lymphoma & 11.4 (range, 10.6-48) \\
\hline \multicolumn{2}{|l|}{ Follow-up (months) } \\
\hline Median & 8 \\
\hline Range & $3.2-23$ \\
\hline \multicolumn{2}{|c|}{ Presenting symptoms, n (\%) } \\
\hline Decrease visual acuity & $11(73.3 \%)$ \\
\hline Periorbital swelling & $5(33.3 \%)$ \\
\hline Eye pain & $2(13.3 \%)$ \\
\hline Proptosis & $1(6.7 \%)$ \\
\hline
\end{tabular}

patients were summarised in Table 3. Patients were followed up monthly after radiotherapy for at least 6 months. The median follow-up duration was 8 months (range, 3.2-26 months). A total of 15 patients were treated. Of the 13 patients with impaired visual acuity before radiotherapy, $11(84.6 \%)$ had improvement. All patients showed improvement in symptoms at 1 month after radiotherapy. One patient (serial No. 9) had further improvement in visual acuity up to 3 months post treatment. In patients who received radiotherapy within 2 months of presentation $(\mathrm{n}=5)$, all had improvement in visual acuity and all had good tumor response. While among the 8 patients who received radiotherapy more than 2 months after presentation, 2 patients had no improvement in visual acuity despite one of them with complete response (CR) in tumor response. The remaining 6 patients had modest improvement in visual acuity only. All patients with periorbital swelling, eye pain, and proptosis had symptom improvement after radiotherapy.

Tumor response was classified as CR, complete tumor shrinkage on imaging and clinical examination; partial response (PR), less than complete tumor shrinkage on imaging and clinical examination; Static disease, no change in tumor volume. Tumor responses for choroidal metastases were documented by eye echography by ophthalmologists. For orbital metastases, responses were documented by imaging either by multi-detector computed tomography (CT) scan or magnetic resonance imaging (MRI). Amongst the fifteen patients who received radiotherapy, 5 (33.3\%) patients had CR, $9(50 \%)$ had PR and 1 (6.6\%) had static disease. One patient had disease rebound in the involved eye 4 months after radiotherapy. All the other patients remained disease free.

Eleven patients had unilateral eye involvement. Seven of them were treated with radiotherapy to the affected eye only and 1 had disease rebound in the same eye 4 months after treatment. 4 patients received irradiation to bilateral eyes for local control of the affected eye and prophylaxis of the contralateral eye. Among the two groups of patients who received radiotherapy to the affected eye only and those who received radiotherapy to both eyes, none of them develop metastases in the contralateral eye within the study period.

The OS curve of the cohort was shown in Figure 1. The median OS was 9.1 months from the diagnosis of orbital metastases (range, 3.2 to 23.6 months). The OS of breast cancer, lung cancer and lymphoma were shown in Figure 2, there was a trend towards longer survival in breast cancer, followed by lymphoma and lung cancer, although the result was not statistically significant.

Toxicities were graded according to Common Terminology Criteria for Adverse Events Version 5.0. All patient tolerated radiotherapy well. One patient experienced mild dryness of the eyes, 2 patients had grade 2 conjunctivitis. All of which resolved within 1 month after 
Table 2 Response and outcome of radiotherapy

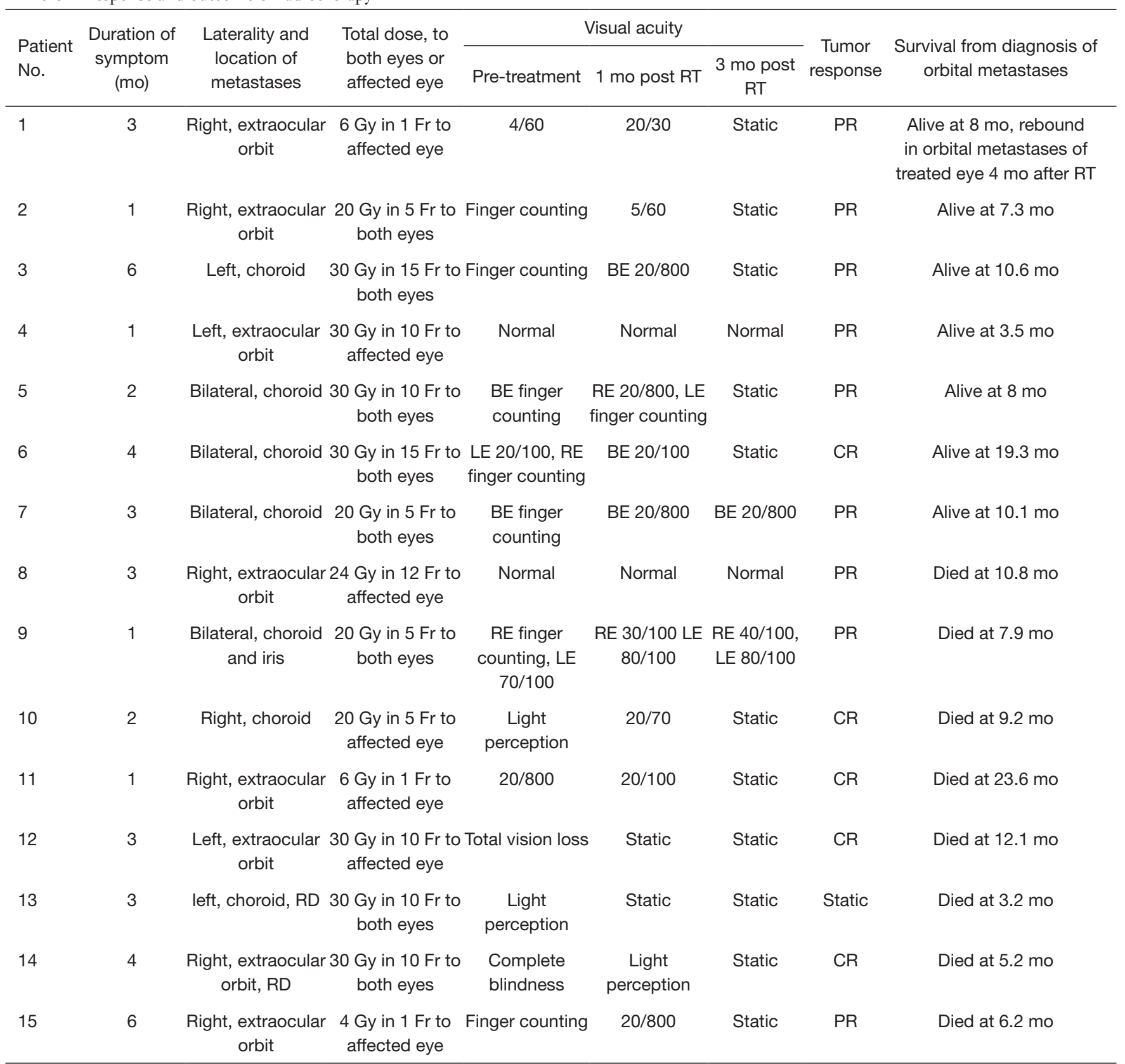

No, number; Mo, months; RT, radiotherapy; Gy, Grays; Fr, fractions; BE, both eyes; RE, right eye; LE, left eye; PR, partial response; CR, complete response; $\mathrm{RD}$, retinal detachment.

completion of radiotherapy none had grade 3-4 reactions. There were no long-term toxicities observed.

\section{Discussion}

Our data showed that breast cancer and lung cancer are the most frequent primary tumor to develop choroidal metastases which is in concordance with the literature findings. The choroid provides a vascular avenue for tumor emboli to sequester and allows an environment receptive to growth. Its high vascular supply accounts for it being the most common site of metastases within the ocular orbit (8). 
Table 3 Symptom response to radiotherapy

\begin{tabular}{ll}
\hline Presenting symptoms & Response to radiotherapy \\
\hline Decrease visual acuity $(n=13)$ & Partial recovery $11(84.6 \%)$, static $2(15.4 \%)$ \\
Periorbital swelling $(n=5)$ & Partial recovery $4(80 \%)$, complete recovery $1(20 \%)$ \\
Eye pain $(n=2)$ & 2 partial recovery $(100 \%)$ \\
Proptosis $(n=1)$ & 1 partial recovery $(100 \%)$ \\
\hline
\end{tabular}

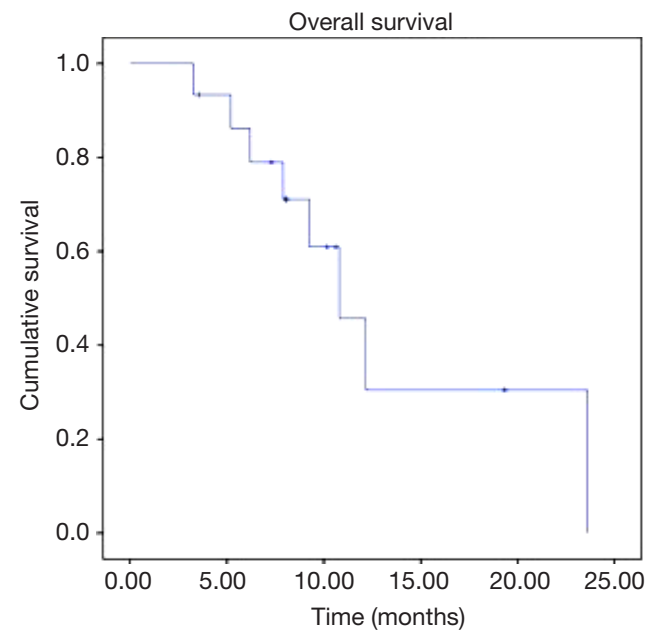

Figure 1 Overall survival of the cohort.

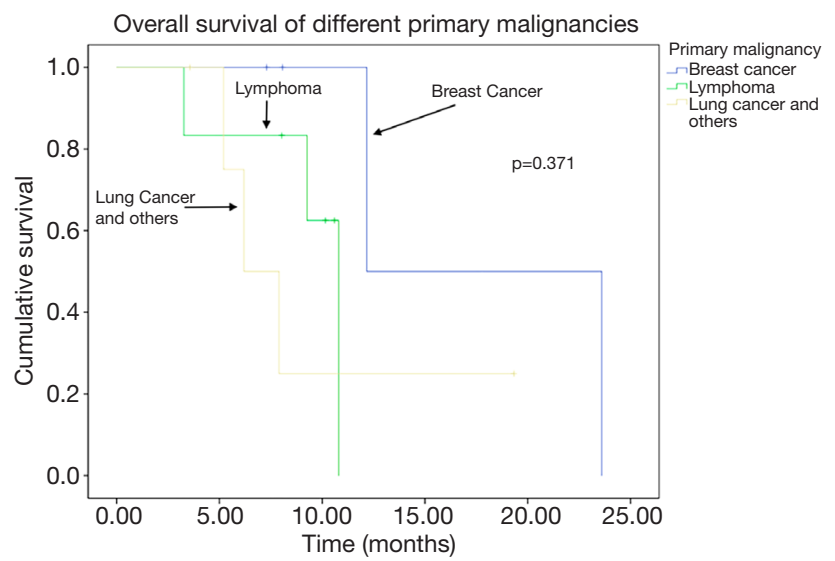

Figure 2 Overall survival of different primary malignancies.

According to some hypothesis, the higher incidence of choroidal metastases in breast cancer could be due to a greater affinity of this tumor type to the eye tissue $(3,9)$. The median interval between diagnosis of primary malignancy to development of choroidal metastases is much shorter for lung cancer (3.2 months) than breast cancer
(24.6 months). This reflects the more aggressive course and shorter life expectancy of lung cancer compared to breast cancer. Thus, higher literature incidence of breast cancer with choroidal metastases can be explained by its long natural history allowing a higher chance of developing metastases to these unusual sites.

External beam radiotherapy (EBRT) has long been used for the treatment of orbital and ocular metastases. Literature review on the studies in palliative radiotherapy for orbit and ocular metastases were reviewed. Owing to the rare entity of this disease, most series were retrospective, carried out over periods of 10-25 years, with great variety of RT technique and radiation dose. Studies reporting outcomes of palliative radiotherapy to the orbit and eye was summarised in Table 4. Most of the series reported use of radiation doses of 20 to 30 Gy in 2 to 4 Gy daily fractions, with a symptom control rate of $57 \%$ to $91 \%(3,7,10$ $12,14)$. In majority of the studies, including the present study, a range of different dose-fractionation, making it difficult to interpret the findings and draw conclusions on the effect of efficacy with increasing dose. In our study, the most commonly used dose-fractionations are $30 \mathrm{~Gy}$ in 10 fractions $(n=5)$ and 20 Gy in 4 fractions $(n=4)$. Other dosefractionations given include: $30 \mathrm{~Gy}$ in 15 fractions $(=2)$, 24 Gy in 12 fractions $(\mathrm{n}=1), 4 \mathrm{~Gy}$ in $1 \mathrm{Fr}(\mathrm{n}=1)$ and $6 \mathrm{~Gy}$ in $1 \mathrm{Fr}(\mathrm{n}=2)$. The results are discussed as follows.

High symptom control rate was achieved with palliative radiotherapy. With a median follow-up of 8 months, eleven patients $(91.6 \%)$ had improvement in visual acuity. For symptoms including periorbital swelling, pain, proptosis, the symptom control rate was $84 \%$ to $100 \%$ (Table 3). 5 patients (33.3\%) had CR, 9 (50\%) had PR and 1 (6.6\%) had static disease, giving an overall response rate (ORR) of $100 \%$. Apart from one patient who developed local progression in the same eye 4 months after radiotherapy, all the other patients remained disease free. The overall median survival was 9.1 months (range, 3.2-23.6 months) from the diagnosis of orbital metastases. These results compare favorably with 
Table 4 Summary of studies on palliative radiotherapy to orbit and eye

\begin{tabular}{|c|c|c|c|c|c|c|c|}
\hline Study & $\begin{array}{l}\text { Number } \\
\text { of eyes/ } \\
\text { patients }\end{array}$ & $\begin{array}{l}\text { Median } \\
\text { follow-up } \\
\quad(\mathrm{mo})\end{array}$ & Dose & $\begin{array}{l}\text { Symptomatic } \\
\text { improvement }\end{array}$ & Local control & Toxicity rate & $\begin{array}{c}\text { Median } \\
\text { survival (mo) }\end{array}$ \\
\hline Huh et al. (11) & $79 / 70$ & NR & 4 Gy in $1 \mathrm{Fr}$ to 50 Gy in $25 \mathrm{Fr}$ & $72 / 79(91.1 \%)$ & NR & Nil & 6 \\
\hline Rudoler et al. (12) & $233 / 188$ & 5.8 & $30-40$ Gy in $10-20 \mathrm{Fr}$ & 89/155 (57.4\%) & 131/143 (91.6\%) & 28/233 (12.0\%) & NR \\
\hline Wiegel et al. (13) & $65 / 50$ & 5.8 & 40 Gy in 20 fractions & $58 / 65(89.2 \%)$ & $65 / 65(100 \%)$ & $3 / 65(4.6 \%)$ & 7 \\
\hline Hahn et al. (14) & $71 / 55$ & 12 & 20 Gy in 5 fractions & $56 / 70(80.0 \%)$ & $66 / 70(94.3 \%)$ & $13 / 71(18.3 \%)$ & 13 \\
\hline Present study & $19 / 15$ & 8 & $\begin{array}{c}30 \mathrm{~Gy} \text { in } 10 \mathrm{Fr}, 20 \mathrm{~Gy} \text { in } 4 \mathrm{Fr} \\
30 \mathrm{~Gy} \text { in } 15 \mathrm{Fr}, 24 \mathrm{~Gy} \text { in } 12 \mathrm{Fr} \\
4-6 \mathrm{~Gy} \text { in } 1 \mathrm{Fr}\end{array}$ & $11 / 13(84.6 \%)$ & 15/15 (100\%) & $\begin{array}{c}2 / 15 \text { (G2 } \\
\text { conjunctivitis) }\end{array}$ & 9.1 \\
\hline
\end{tabular}

NR, not reported.

previously published series of longer dose fractionation schedules. In the series by Rudoler et al. (12), 70\% of patients received 30 to 40 Gy in 2- to 3-Gy daily fractions, and visual acuity improved or was stable in $57 \%$ of eyes with a median follow-up of 5.8 months (12). Rosset et al. showed similar results with stable or improved visual acuity in $62 \%$ of patients who were treated with a median dose of $35.5 \mathrm{~Gy}$ in 2-Gy daily fractions, but median follow-up duration was not clearly reported (3). Wiegel et al. reported that $89 \%$ of patients experienced stable or improved visual acuity with a median follow-up of 5.8 months after treatment with 40 Gy in 2-Gy daily fractions (7). The result observed in our study is comparable to other series in terms of response and toxicities though our cohort size was smaller than others. Shorter treatment courses give the benefit of reducing patients' traveling time to attend treatment and relieve the burden of the health care system.

Timely recognition of ocular and orbital metastases improves the patient's quality of life. All patients who receive radiotherapy within 2 months of onset of symptoms had improvement in vision and orbital symptoms, with good tumor control achieved. In patients who received radiotherapy more than 2 months after presentation, 2 had no improvement in visual acuity despite one of them had CR in tumor response. The remaining 6 patients had modest improvement in visual acuity only. This reflects the importance of timely diagnosis and local treatment for these patients to preserve vision.

A common presentation of choroidal metastases is retinal detachment. Among the seven patients with choroidal metastases, two patients (serial number 13 and 14) had retinal detachment on presentation and were initially given usual therapeutic treatments for retinal detachment. During subsequent follow-up, a choroidal mass was found on ophthalmological examination and confirmed the presence of choroidal metastases. These two patients received radiotherapy at 3 months and 4 months after onset of symptoms. One patient had no improvement in vision after radiotherapy, another patient had modest improvement from complete blindness to light perception. A high index of suspicion is necessary especially when approaching patients with history of malignancy presenting decreased vision. Allowing timely palliative treatment to preserve vision.

The treatment-of-choice for unilateral metastases remains controversial. In our study, among the 11 patients had unilateral eye involvement. Seven of them were treated with radiotherapy to the affected eye only, while 4 patients received irradiation to bilateral eyes for local control of the affected eye and prophylaxis of the contralateral eye. In both groups, none of them develop metastases in the contralateral eye during the study period. The reported incidence of bilateral choroidal metastases at the time of diagnosis was up to $20-40 \%$ from the literature (4). In the study by Rosset et al., they noted that three out of 26 patients $(11 \%)$ with unilateral disease developed contralateral metastases when only the involved eye was irradiated. Whereas none were observed in those who received bilateral irradiation (0/10). Based on their work they advocated bilateral irradiation for sterilization of contralateral disease (3). In a prospective study by the German Cancer Society (ARO 95-08), thirtyfive out of 50 patients with choroidal metastasis had unilateral disease and received unilateral irradiation with a 
lateral field a dose of $40 \mathrm{~Gy}$ in 20 fractions without sparing the contralateral choroidea. The posterior contralateral choroid received $50-70 \%$ of the total dose (20-28 Gy) for suspected micrometastasis. None of these patients developed contralateral choroidal metastasis during the median follow up time of 11.5 months. Based on this result the author supported the treatment of unilateral choroidal metastases with unilateral field giving $50-70 \%$ of the prescribed dose to the contralateral choroid (13). In our study, both the unilateral and bilateral irradiation group did not develop contralateral metastases. Although the small sample size make it difficult to draw any conclusions. The risk of severe side effects such as retinopathy was reported in up to $5 \%$ when doses between $30 \mathrm{~Gy}$ in $10 \mathrm{Fr}$ and $40 \mathrm{~Gy}$ in $20 \mathrm{Fr}$ were given $(12,15)$. Furthermore, new and more effective systemic have evolved and improved disease control in patients compared to the past. It seems a reasonable option to treat only the affected eye and consider irradiating the contralateral eye when metastases occur.

\section{Alternative treatment}

Modern radiotherapy techniques such as stereotactic radiosurgery or fractionated stereotactic radiotherapy (SRT) (16) and proton beam therapy (17) have been deployed for managing orbital and choroidal metastases. The largest study on SRT comprised 57 eyes, documenting $100 \%$ control in grade 1 lesions and $63 \%$ response in all choroidal metastases overall, over a mean follow-up of 7 months (16). In a retrospective study of 76 eyes treated with photon beam therapy (PBT), complete regression was observed in $84 \%$ within 5 months with no recurrence after a mean follow-up of 10 months. Associated serous retinal detachments resolved in $82 \%$ of patients within 3.8 months (17). Plaque brachytherapy has also been applied in some series. In one retrospective study of 36 patients, lesion regression was noted in $94 \%$ of patients at a mean follow-up of 11 months. Complications were seen in $8 \%$ of patients and included radiation retinopathy, papillopathy, and cataract in anteriorly placed plaques (18).

Less invasive local treatment modalities have emerged in the present era. Laser photocoagulation, photodynamic therapy and intravitreal injection of anti-VEGF may also help to preserve vision while reducing time spent in medical settings for patients in palliative care. Transpupillary thermotherapy, cryotherapy, local excision and even enucleation have been used as other local treatment modalities $(19,20)$.
With the advancement in systemic therapies, more effective systemic treatment achieving good tumor control with tolerable side effects has emerged. Current evidence shows that triple negative and HER2-positive breast cancer have higher rate of brain metastases, but hormonal receptor positive cases are more likely to develop choroidal metastases (21), making therapy with tamoxifen and aromatase inhibitors effective $(22,23)$. Molecular targeted therapies led to paradigm shift in the treatment of lung cancer, and there is increasing number of publications reporting the effectiveness of systemic treatments on choroidal metastases (9).

\section{Treatment toxicities}

Most side effects from external beam RT are mild and self-limiting. Common side effects of external beam RT include acute conjunctivitis, keratitis. Rare and serious side effects that could occur include cataracts, radiation induced retinopathy, and papillopathy in up to $5 \%$ of patients $(10,12,15)$. In a series by Rudoler et al. (12), 483 cases of ocular metastases received palliative EBRT were reviewed. There were sixteen cataracts (3.3\%), 6 cases of radiation retinopathy $(1.2 \%), 6$ cases of exposure keratopathy $(1.2 \%), 5$ cases of optic neuropathy (1\%) and 4 cases of neovascularisation of the iris (1\%). Factors including a higher biologically effective dose, lower treatment energy and whole globe $v s$. lens sparing technique did not predispose treated eyes to complications including cataract. Nevertheless, care should be taken to spare the lens during radiotherapy. Literature studies have shown that factors including diabetes mellitus, hypertension and chemotherapy administration were shown to enhance retinal sensitivity to radiation injury at lower dose (24-26). Patients with choroid metastases have a median survival of 9 months, as with our cohort, but the development of cataract after radiation may take up to 4-8 years (12). Careful balance between benefit and risk should be excised when offering radiotherapy to patients who are expected to have longer life span, as patient who survives longer have higher rate of long-term complications, compared with patients who die early of systemic disease. On the other hand, because the risk of complications in patients with a relatively short expected life span is quite low, RT should be offered to these patients without reservations.

\section{Survival}

The OS curve of the cohort was shown in Figure 1. The median OS was 9.1 months (range, 3.2 to 23.6 months), 
comparable with the historical cohorts. The short survival reflects the poor prognosis of patients with orbital or ocular metastases. The presence of orbital or ocular adnexal metastatic lesions usually reflects the widespread hematogenous spread of the primary cancer and carries a poorer prognosis compared to other sites of metastases (5). Figure 2 showed the OS curves of breast cancer, lymphoma, lung cancer and other cancers. It showed that there is a trend of separation of the three curves, with the longest survival being breast cancer, followed by lymphoma and lung cancer. Although the sample size was too small to draw any statistically significant result, it reflects the aggressiveness of the three diseases in the same order.

\section{Limitations of study}

There are several limitations to this study. The heterogeneity of the treatment regimen may be associated with underlying bias. Given the retrospective nature of this study, not all patients had follow-up at predetermined intervals, and some of the data were missing at certain time-points. Additionally, retrospective assessment of acute and late toxicities was limited by the retrospective chart review. The small sample size also makes it difficult to draw any statistically significant conclusions. Given the limitations, the outcomes and survival results of our cohort are comparable with the results from historical cohort, confirming the efficacy of short-course palliative radiotherapy.

\section{Conclusions}

Short course palliative RT is effective and well tolerated in patients with orbital and ocular metastases. The current report showed that it effectively preserves vision and improves orbital symptoms with minimal radiation induced toxicity. Short course radiotherapy will help to minimize the traveling time to the hospital and relieve the burden of a long treatment course in this palliative patient population. Further prospective study is warranted in determining the optimal treatment dose for these patients.

\section{Acknowledgments}

Funding: None.

\section{Footnote}

Provenance and Peer Review: This article was commissioned by the Guest Editors (Rebecca Yeung and Tai Chung Lam) for the series "Integrating Palliative Medicine in Oncology Care: The Hong Kong Experience" published in Annals of Palliative Medicine. The article has undergone external peer review.

Conflicts of Interest: All authors have completed the ICMJE uniform disclosure form (available at http://dx.doi. org/10.21037/apm.2019.12.02). The series "Integrating Palliative Medicine in Oncology Care: The Hong Kong Experience" was commissioned by the editorial office without any funding or sponsorship. The authors have no other conflicts of interest to declare.

Ethical Statement: The authors are accountable for all aspects of the work in ensuring that questions related to the accuracy or integrity of any part of the work are appropriately investigated and resolved. The study was conducted in accordance with the Declaration of Helsinki (as revised in 2013). The study was approved by Research Ethics Committee of Kowloon Central Cluster, Hospital Authority (Ref: KC/KE-19-0232/ER-2) and informed consent has been waived.

Open Access Statement: This is an Open Access article distributed in accordance with the Creative Commons Attribution-NonCommercial-NoDerivs 4.0 International License (CC BY-NC-ND 4.0), which permits the noncommercial replication and distribution of the article with the strict proviso that no changes or edits are made and the original work is properly cited (including links to both the formal publication through the relevant DOI and the license). See: https://creativecommons.org/licenses/by-nc-nd/4.0/.

\section{References}

1. Fernandes BF, Fernandes LH, Burnier MN, Jr. Choroidal mass as the presenting sign of small cell lung carcinoma. Can J Ophthalmol 2006;41:605-8.

2. Kreusel KM, Wiegel T, Stange M, et al. Choroidal metastasis in disseminated lung cancer: frequency and risk factors. Am J Ophthalmol 2002;134:445-7.

3. Rosset A, Zografos L, Coucke P, et al. Radiotherapy of choroidal metastases. Radiother Oncol 1998;46:263-8.

4. Shields CL, Shields JA, Gross NE, et al. Survey of 520 eyes with uveal metastases. Ophthalmology 1997;104:1265-76.

5. Ahmad SM, Esmaeli B. Metastatic tumors of the orbit and ocular adnexa. Curr Opin Ophthalmol 2007;18:405-13. 
6. Freedman MI, Folk JC. Metastatic tumors to the eye and orbit. Patient survival and clinical characteristics. Arch Ophthalmol 1987;105:1215-9.

7. Wiegel T, Bottke D, Kreusel KM, et al. External beam radiotherapy of choroidal metastases--final results of a prospective study of the German Cancer Society (ARO 9508). Radiother Oncol 2002;64:13-8.

8. Avram AM, Gielczyk R, Su L, et al. Choroidal and skin metastases from papillary thyroid cancer: case and a review of the literature. J Clin Endocrinol Metab 2004;89:5303-7.

9. Mathis T, Jardel P, Loria O, et al. New concepts in the diagnosis and management of choroidal metastases. Prog Retin Eye Res 2019;68:144-76.

10. Roy S, Madan R, Gogia A, et al. Short course palliative radiotherapy in the management of choroidal metastasis: An effective technique since ages. J Egypt Natl Canc Inst 2016;28:49-53.

11. Huh SH, Nisce LZ, Simpson LD, et al. Proceedings: Value of radiation therapy in the treatment of orbital metastasis. Am J Roentgenol Radium Ther Nucl Med 1974;120:589-94.

12. Rudoler SB, Corn BW, Shields CL, et al. External beam irradiation for choroid metastases: identification of factors predisposing to long-term sequelae. Int J Radiat Oncol Biol Phys 1997;38:251-6.

13. Wiegel T, Kreusel KM, Schmidt S, et al. Radiotherapy of unilateral choroidal metastasis: unilateral irradiation or bilateral irradiation for sterilization of suspected contralateral disease? Radiother Oncol 1999;53:139-41.

14. Hahn E, Laperriere N, Krema H, et al. Clinical outcomes of hypofractionated radiation therapy for choroidal metastases: Symptom palliation, tumor control, and survival. Pract Radiat Oncol 2017;7:388-95.

15. Wiegel T, Kleineidam M, Schilling A. Choroid metastasis in a patient with adenocarcinoma of the cervix. A case report. Strahlenther Onkol 1995;171:539-42.

Cite this article as: Chik JYK, Leung CWL, Wong KH. Palliative radiation therapy for patients with orbital and ocular metastases. Ann Palliat Med 2020;9(6):4458-4466. doi: 10.21037/apm.2019.12.02
16. Bellmann C, Fuss M, Holz FG, et al. Stereotactic radiation therapy for malignant choroidal tumors: preliminary, short-term results. Ophthalmology 2000;107:358-65.

17. Tsina EK, Lane AM, Zacks DN, et al. Treatment of metastatic tumors of the choroid with proton beam irradiation. Ophthalmology 2005;112:337-43.

18. Shields CL, Shields JA, De Potter P, et al. Plaque radiotherapy for the management of uveal metastasis. Arch Ophthalmol 1997;115:203-9.

19. Chu CK, El-Annan J. Photodynamic therapy for choroidal carcinoid metastasis. Can J Ophthalmol 2018;53:e13-6.

20. Kiratli H, Bilgic S. Transpupillary thermotherapy in the management of choroidal metastases. Eur J Ophthalmol 2004;14:423-9.

21. Parrozzani R, Frizziero L, Testi I, et al. Intraocular Metastases Secondary to Breast Carcinoma Correlates With Upregulation of Estrogen and Progesterone Receptor Expression in the Primary Tumor. Invest Ophthalmol Vis Sci 2016;57:3944-8.

22. Manquez ME, Brown MM, Shields CL, et al. Management of choroidal metastases from breast carcinomas using aromatase inhibitors. Curr Opin Ophthalmol 2006;17:251-6.

23. Logani S, Gomez H, Jampol LM. Resolution of choroidal metastasis in breast cancer with high estrogen receptors. Arch Ophthalmol 1992;110:451-2.

24. Brown GC, Shields JA, Sanborn G, et al. Radiation retinopathy. Ophthalmology 1982;89:1494-501.

25. Parsons JT, Bova FJ, Fitzgerald CR, et al. Radiation retinopathy after external-beam irradiation: analysis of time-dose factors. Int J Radiat Oncol Biol Phys 1994;30:765-73.

26. Viebahn M, Barricks ME, Osterloh MD. Synergism between diabetic and radiation retinopathy: case report and review. Br J Ophthalmol 1991;75:629-32. 